\title{
Tear, Rip or Hole in Packaging
}

National Cancer Institute

\section{Source}

National Cancer Institute. Tear, Rip or Hole in Packaging. NCI Thesaurus. Code C62831.

Problem associated with packaging damage (tear, rip or hole) prior to the use of the device. 